\title{
The Attitudinal Opacity of Emotional Experience
}

\author{
Jonathan Mitchell (University of Manchester) - jonathan.mitchell@manchester.ac.uk \\ forthcoming in Philosophical Quarterly (please do not quote without permission).
}

\begin{abstract}
According to some philosophers, when introspectively attending to experience, we seem to see right through it to the (apparent) objects outside, including their properties. This is called the transparency of experience. This paper examines whether, and in what sense, emotions are transparent. It argues that emotional experiences are opaque in a distinctive way: introspective attention to them does not principally reveal non-intentional somatic qualia but rather felt valenced intentional attitudes. As such, emotional experience is attitudinally opaque.
\end{abstract}

\section{Introduction}

When we introspectively focus on experience itself, rather than what experience is about or directed toward, we arguably find nothing to attend to but (apparent) objects and their properties. As it is sometimes put, we seem to see right through experience to the objects (apparently) outside, including their properties. Consider introspectively attending to a visual experience of a red and round ball. According to some philosophers, the only properties that seem salient - the only properties that capture how things are experientially for me - are properties of the (apparent) external object, that is redness and roundness as represented properties of the ball, not any 'intrinsic' properties of the experience.' This reflects the so-called transparency of experience. What is entailed by it concerning the correctness of specific theories of perceptual experience - for example, sense-datum theory, strong representationalism, intentionalism, naïve realism - will not concern me here. The transparency of experience is a phenomenological rather than metaphysical claim, concerning how (and what) properties seem to figure in introspective attention to

\footnotetext{
I See Tye 1995: 30; Moore 1903: 446, 450; Harman 1990: 38; 1996: 8-9, 14; Shoemaker 1996: 100, 132, 257; Tye 1992: 160; 2002: 139; Martin 2002: 380-81; Speaks 2009: 542.
} 
experience, as characterizing its phenomenal character (or at least this is how I will understand it). ${ }^{2}$

This paper examines whether, and in what sense, emotional experiences are transparent. It argues that they are opaque in a distinctive way: introspective attention to emotional experiences does not principally reveal non-intentional somatic qualia but felt valenced intentional attitudes - hence the attitudinal opacity of emotional experience. This claim is a phenomenological one, and although it has implications for theories of emotion, I don't consider those here. ${ }^{3}$ The structure of the paper is as follows. Section I provides a discussion of transparency and opacity. Section 2 considers how transparency and opacity claims apply to emotional experience, arguing that, contrary to the consensus view in emotion theory, emotional experiences are not opaque in virtue of their somaticity. Finally, section 3 makes a case for attitudinal opacity.

\section{Preliminaries on Transparency}

\section{I Transparency and opacity}

Let me clarify different claims concerning transparency and opacity.

Transparency claim: when S introspectively attends to their intentional experience the only properties $\mathrm{S}$ seems aware of are properties of the object of the experience.

This claim was expressed in the introduction. It is also what is contested by qualia theorists. ${ }^{4}$ Simply put, when introspecting there are no non-object involving properties $\mathrm{S}$ seems aware of. Note, this formulation does not commit to the relevant objects and their properties necessarily being presented as part of the subject's external environment (although this would be the case for sense-perceptual experience). In certain cases, the relevant objects may be parts of our body or bodily sensations. So, the transparency claim covers both exteroceptive and interoceptive experiences.

2 Gow 2016: 723-9, Kennedy 2009: 574-6 and Tye 2014: 39-57 recognise this. Although, if (phenomenological) transparency is true, it creates a presumption in favour of whichever metaphysics of perception best explains it (see Gow 2016: $732-736$ and Siewert 2003: 15-4I for discussion).

${ }^{3} \mathrm{NB}$ : The opacity of emotional experience is often raised as an objection to the perceptualist model of emotion (see Tappolet 2016: Ch. I).

${ }^{4}$ See Block 1996: 19-49 2003: 165-200; Burge 2003: 405-I5; Shoemaker 1996: ch.5, ch.6. Kind 2003: 225244; Peacocke 1983. 
Strongest opacity claim: when S introspectively attends to their intentional experience the properties which pre-reflectively seemed to be properties of the object of the experience, now seem to be properties of the experience itself.

Take a visual experience of a brown table. Before introspective attention brownness seemed like a property of the table, a way the table (phenomenally) looked. Now - upon introspectively attending to the experience - brownness purportedly seems like a property of the experience; the colour property which seemingly qualified the object of the experience now seems to qualify the experience itself.

Those defending the transparency claim reject the strongest opacity claim. ${ }^{5}$ The principal reason being that my experience does not seem (in introspection) red and round but seems to be of something red and round. Insofar as the transparency claim has intuitive appeal, some of it derives from the phenomenological implausibility of the strongest opacity claim. Objects of experience can certainly seem red and round; whereas experiences themselves never seem red or round. Indeed, it is unclear what one's experience seeming red and round could amount to. ${ }^{6}$

However, we are not forced into accepting the strongest opacity claim by denying the transparency claim. There are two further claims which deny the latter without accepting the former.

Strong opacity claim: when S introspectively attends to their intentional experience the properties S seems to be aware of are exclusively non-object involving properties. These are not the (apparent) object-properties, qualified of the experience itself. Rather S's attention is directed toward subjective non-object involving properties.

Consider again a visual experience of a brown table. Prior to introspective attention, brownness seemed like a feature of the table. However, introspective attention to the experience now 'turns away' from the (apparent) object and its properties, toward non-

\footnotetext{
${ }^{5}$ See Tye 2002: 138 and Harman 1990: 39; 1996: 8.

${ }^{6}$ One could endorse a metaphysics (in this case of colours) which claimed that, pace the phenomenology, the properties perceived as qualifying the objects of visual experience are in fact properties of the experiences. Shoemaker (1996: I17) calls this literal projectivism.
} 
object involving properties. I consider possible candidates for what such properties are after outlining a final claim.

Arguably the strong opacity claim is too strong. Even if introspective attention to intentional experience can reveal non-object involving properties, it also involves attention to the object of the experience and its properties. ${ }^{7}$ Given this, consider the following:

Weak opacity claim: when S introspectively attends to their intentional experience, the properties S seems aware of are mostly properties of the object of the experience. Further to this, the experience still seems to be of something that has those properties, rather than itself having those properties. Yet, there are also non-object involving properties $\mathrm{S}$ seems aware of that are not (apparent) object-properties.

The weak opacity claim rejects both the strongest and strong opacity claims. Nonetheless, it denies the exclusivity of the transparency claim: introspective attention to experience putatively reveals that phenomenal character outruns intentional content since there are also non-object involving properties $\mathrm{S}$ seems aware of.

Defenders of the transparency claim also reject the strong and weak opacity claims. ${ }^{8}$ Note that for those who think that the transparency of experience stands and falls with the transparency claim, the idea of an experience being weakly transparent - and so a framing of the weak opacity claim as the weak transparency claim (as Amy Kind does) - will be confused. ${ }^{9}$ Either the experience seems transparent, as outlined in that claim, or does not, and so is in some respect and degree phenomenologically opaque. Given this, I talk in terms of the weak opacity claim, and of an experience being opaque when it doesn't satisfy the transparency claim.

\subsection{Mental Paint and Mental Latex}

Let's now examine non-object involving properties of experience. Getting a substantial proposal here is crucial since some philosophers deny any sense can be given to the closely related notion of qualia. ${ }^{10}$ Drawing on discussion by Ned Block, we can distinguish two

\footnotetext{
${ }^{7}$ See Siewert 2003: 35.

${ }^{8}$ See Tye 2002: 141.

${ }^{9}$ See Kind 2003: 233 (cf. Tye 2014: 52-53).

10 See Dennett 1988; Martin 1998: 157-79.
} 
candidates, namely mental paint and mental latex." These aren't the only characterizations of non-object involving properties of experience one can give, they are, however, the ones considered here. ${ }^{12}$

Mental paint is properties of the experience that play an intentional role and so which allow for the representation of the object and its properties. For example, in the case of a sense-perceptual experience of a red and round ball, the mental paint would be the component of the experience (if there is such) that represents redness and roundness the so-called vehicle of representation. There should be no confusion that because mental paint play a representational role that these vehicular properties are object-involving in the sense of the transparency claim. The properties which figure in that claim are the (apparent) properties of the object represented, and mental paint is not that, and therefore is not part of the intentional content of experience. ${ }^{13}$ So understood, we avoid conflating the (apparent) properties of what is represented (i.e. properties of the intentional object of the experience) and properties of the (putative) vehicle of representation, as properties of what is doing the representing. One way of thinking about mental paint, which I return to, is as intentional modes or attitudes. ${ }^{14}$

Alternatively, mental latex are properties of the experience which are (a) not objectproperties, and (b) don't play any representational role. These would be mere accompaniments to experience, akin to Reidian raw feels, or perhaps aspects of the phenomenological background. If experiences include mental latex we have a second candidate non-object involving property.

Consider the following analogy which attempts to precisify mental paint and latex. ${ }^{15}$ When looking through a window, we mostly see right through it to what's on the other side. But with an attention switch, we can focus on the pane of glass itself. The pane of glass is akin to mental paint; it plays a representational role - it is that through which we see out of the window - and arguably, we can become aware of it as such. However, the glass may also have marks on it. These would be analogous to mental latex. They are

\footnotetext{
II See Block 1996: 19-49; 2003: 165-200 (Harman 1990: 39 introduces the term mental paint).

${ }^{12}$ Cf. Shoemaker 1996: 268.

13 Mental paint might, however, given its intentional role, be characterized, as part of the intentional nature of a state, and so would not be characterized as qualia on a definition of the latter as not part of that intentional nature (see Crane 2009: 481).

${ }^{14}$ See Crane 2000: I- I I; 2009: 474-49 I (see also Searle 1983: 4-6, I2).

15 The example is amended from Kind 2003: 233 (cf. Tye 2014: 52-53).
} 
features of the experience that are (putatively) there in the phenomenology, and so which we should, in principle, be able to become aware of through introspection. But they don't play any representational role. ${ }^{16}$

Are mental paint and latex, on the above characterizations, intrinsic features of experience, and in positing them are we committed to such a metaphysical claim? The terminology is Harman's, who denies we are ever introspectively aware of intrinsic features of experience. ${ }^{17}$ The answer for our purposes is no: insofar as we take the transparency and opacity claims phenomenologically - as claims about how things experientially seem for subjects introspectively attending to their experiences - there is no commitment to the metaphysical status of these properties. This is as true of the object-properties as of any (putative) non-object involving properties. ${ }^{18}$

Let me now say more about introspection. Tye claims that 'when we introspect our experiences... we become aware of what it is like to undergo them' and that 'introspection of phenomenal character is a reliable process that takes awareness of external qualities (in the case of perceptual sensations) as input and yields awareness that a state is present with a certain phenomenal character as output.. ${ }^{19}$ However, we shouldn't beg the question - as the second passage does in talk of only taking object-properties as input - in favour of the transparency claim by defining introspection such as to ex hypothesi rules out opacity claims.

We can, however, adopt neutral parts of this characterization. Introspection either is or involves conscious attention to how things are experientially with one. Building on this, it is widely held that introspection is a reliable process which moves from phenomenal awareness to conceptually articulated propositional knowledge that one is having an experience with this phenomenal character. Introspective awareness is, therefore, cognitively sophisticated; it is doxastic fact-awareness, and in the case of experiential states it is awareness of the fact that one's experience has such and such phenomenal character. ${ }^{20}$ This may typically involve the fact that one enjoys phenomenal awareness of (apparent)

\footnotetext{
16 This interpretation of mental latex echoes Tyler Burge's suggestion that non-representational features of experience are 'noise in the medium of representation' (Burge 2003: 407).

17 See Harman 1990: 38-40.

18 This is signalled by Tye $(2002: 138,142)$, concerning the object-properties, and the intrinsic terminology is latter jettisoned (see Tye 2014: 40).

19 See Tye 2002: 144, 146.

${ }^{20}$ See Dretske 1999: 158-177 and Tye 2014: 41-42.
} 
object-properties, but should also, in principle, include whatever else is experientially present.

Given this characterization, we still avoid the problematic 'object-perceptual' notion of introspection - the view that one 'senses' one's mental states in a way analogous to senseperception. ${ }^{21}$ Introspection does, however, require the deployment (and possession) of the relevant phenomenal concepts, for example, recognitional concepts associated with objectproperties (e.g. redness). However, prior to determining the truth of the transparency claim for the relevant class of intentional experiences, we should not assume that the repertoire of recognitional concepts is exhausted by concepts relating to object-properties. For example, there may be phenomenal-recognitional concepts relating to mental paint and latex.

\section{The Opacity of Emotional Experience}

\section{I Emotional experience and evaluative properties}

I now provide an outline of emotional experiences and their content.

Emotional experiences are occurrent episodes, usually of relatively short duration, enjoyed by individuals at particular times. As such, they are first-person states that have a what-it-is-likeness; there is something-it-is-like to be the subject of episodic fear, love, shame, regret, or admiration. Emotional experiences are, therefore, conscious states with a felt phenomenology. ${ }^{22}$ In addition, paradigmatic emotional experiences are intentional states, in at least the minimal sense that they are directed towards objects, such as physical particulars, persons, animals, events, and states of affairs. Emotion theorists label these the particular objects of emotions, as the target or focus of the emotion. ${ }^{23}$ For example, the particular object of fear could be a bear (animal); of anger, my partner (person); of embarrassment, my having arrived late (event). Given this, the first-order intentionality of emotional experience isn't a kind of introspection; having the emotional experience and introspecting it are tokenings of different mental states. ${ }^{24}$ Note also, that introspectable emotions, as emotional experiences, are necessarily felt. If, as seems plausible, there are unfelt emotions, then they will not be introspectable.

\footnotetext{
${ }^{21}$ See Shoemaker 1996: 201-246.

22 See Deonna and Teroni 20 I2: Ch. I; Goldie 2002: 235-54; Montague 2009: I71-92.

${ }^{23}$ See Lyons 1980: 104-6; de Sousa 1987: I16; Teroni 2007: 395-4I5.

${ }^{24}$ See Seagar 2002: 674.
} 
The nature of emotional phenomenology, especially how it relates to the intentional aspects of emotional experience, is a complex issue. For now, note that as the subject of object-directed episodic grief, for example, one may experience, in addition to a particular object (the event of Bill's death), somatic sensations and a range of other phenomenal components. For example, there may be an attentional switch and personal level psychological attitudes. Remember, we are leaving it open for now whether any or all of this phenomenology can be cashed out in terms of intentional content.

Building on the above, contemporary accounts suggest emotional intentionality is more complicated than can be captured by reference to particular objects. Emotional experiences also arguably involve 'formal objects'. Formal objects are, in general, properties allowing for categorization of different mental state kinds. In the case of emotions, the relevant formal objects are specified in terms of thick evaluative properties, such as the beautiful, offensive, disgusting, fearsome, funny, and admirable. Formal objects would, therefore, in some sense qualify emotions, supporting type-identification of the relevant emotion. ${ }^{25}$ On one way of developing this point, paradigmatic emotional experiences represent their particular objects under evaluative aspects. As such, their intentional content would be partly specified in terms of relevant evaluative properties. For example, indignation would not just represent its particular object, say a colleague's remark, but would represent it as offensive; fear would not just represent its particular object, say a barking Alsatian, but would represent it as fearsome.

It is also worth noting a different view of emotional content. Some theorists resist specifying the content of emotional experience as evaluative. Rather, it is suggested emotional experiences represent their particular objects as possessing non-evaluative, evaluatively-relevant, properties. For example, in an occurrent episode of fear, my fear may be directed toward the Alsatian, under evaluatively-relevant aspects, such as its loud bark, sharp teeth, impulsive behaviour, etc. ${ }^{26}$ However, whether we adopt the evaluative content view or this alternative, according to both emotional experience involves the representation of properties of its particular object. I mostly talk of evaluative properties from here on, but the discussion could be framed in terms of non-evaluative, evaluativelyrelevant properties.

\footnotetext{
25 See Kenny 1963: 132 and Teroni 2007: 395-4I5.

${ }^{26}$ See Deonna and Teroni 2012: 76-89. Deonna and Teroni claim values qualify the attitude component of emotions, rather than their content.
} 
Finally, note that it is sometimes suggested that emotions have a sui generis affective intentionality which goes beyond evaluative intentionality per se. If one were to take the supposed sui generis affective intentionality of emotional experience as the phenomenological starting point in need of explanation, then arguably - given a construal of affective intentionality along the lines of mental paint - some form of the weak opacity claim would emerge as the most promising account at the outset. As will become apparent, I am sympathetic to this result (see section 3.3 and 3.4). However, the notion of a sui generis affective intentionality for emotions is nonetheless contentious and needs unpacking. So, in this context, it is best to frame such proposals as emerging from investigation of the issues concerning transparency and opacity broached over the following sections.

\subsection{Emotional Experience and transparency}

Now that we have an outline of emotional experience, let's build it into the transparency claim:

Transparency claim for emotional experience (hereafter TE): when S introspectively attends to their emotional experience the only properties $S$ seems aware of are evaluative properties of the particular object of the experience.

Say I introspect my experience of aesthetic admiration toward a painting. In doing so, I should see right through the experience to properties it represents - in this case, evaluative properties of the painting, such as its determinate beauty. Similarly, if I was to introspect my experience of empathy for a friend, I should see right through the experience to evaluative properties of their situation, e.g. that they are having a sorrowful time. ${ }^{27}$

Let's now consider the strongest opacity claim by way of contrast.

Strongest opacity claim for emotional experience: when S introspectively attends to their emotional experience the evaluative properties which pre-reflectively seemed to be properties of the particular object of the experience, now seem to be properties of the experience itself.

${ }^{27}$ See Tappolet 20 I6: 27-8. 
For this claim to be true those evaluative (or evaluatively-relevant) properties should now seem to qualify the experience itself. But this looks like a phenomenological non-starter. If anything in emotional experience seems fearsome it is that at which my fear is directed, not my experience. This is not to deny that an experience can seem fearsome, for example, if one takes it as a symptom of disease; a persistent migraine might seem fearsome if one takes it to indicate a tumour. Yet, such cases are not - as the strongest opacity claim requires - cases where an instance of an evaluative property which pre-reflectively seemed to qualify the object of the experience then, in the move to introspection, qualifies the experience. Instead, we have a case where an experience itself is the particular object of an emotion. What seems fearsome is the migraine experience my emotion is directed towards, and introspection on that emotional experience would still present fearsomeness as a property of that migraine experience, and not as a property of the emotional experience itself. Likewise, an LSD hallucination may, as the object of admiration, seem beautiful. But again, in introspection on my aesthetic admiration, what seems beautiful is the LSD hallucination, not my emotional experience of it.

So, the TE is in good shape given that (i) introspective attention can focus on the particular objects of emotional experiences and their evaluative properties, and (ii) the strongest opacity claim for emotional experiences is implausible.

\subsection{Somatic Opacity}

Yet, the consensus in contemporary emotion theory is that the TE is false. The principal reason is the presence of somatic properties. Here are indicative statements:

If you are to describe how it feels to be frightened by a spider, you would not do so in terms of the spider's qualities, but rather in terms of how it feels to experience a jolt up your spine, your hair standing on end, your teeth clenching, muscles freezing, heart jumping etc. And these felt changes in your body are definitively not what you apprehend as dangerous in the circumstances. (Deonna and Teroni 2012:69)

When the angry man, or the joyful bride, or the jealous husband attempt to describe the world, they succeed only in describing their own state of mind, or perhaps even just the hormonal... balance in their body. (de Sousa 2004: 64) 
An attempt to describe an emotional experience may succeed only in portraying the subject's own state of mind/body - angry, sad, happy, excited and so on - even if the emotion relates to some object in the world. (Salmela 20 I I: 25)

Consider...the new father... If he were to describe his experience of happiness, probably, he would say things like: "I feel great inner warmth", "I feel like I could hug the world", "I feel like I could fly", etc. Certainly, he would not just describe the baby as rosy and wonderful. (Lutz 2015: 321-22).

Deonna and Teroni and de Sousa commit (in part) to a version of the strong opacity claim: when $\mathrm{S}$ introspects their emotional experience the properties $\mathrm{S}$ seems aware of are exclusively non-object involving (principally somatic) properties. Salmela and Lutz are closer to the weak opacity claim: when S introspects their emotional experience, some of the properties $S$ seems aware of are evaluative (or evaluatively-relevant) properties of the particular object. Yet, S also seems aware of non-object involving (principally somatic) properties.

The authors are appealing to what we can call (following discussion in section I) somatic latex. ${ }^{28}$ Emotional experiences run afoul of the TE since their phenomenal character, as revealed in introspection, includes somatic latex. In this context, we are appealing to mere somatic accompaniments (somatic 'raw feels'), or somatic properties which are part of the phenomenological background. We, therefore, have a presumption in favour of a kind of somatic opacity.

However, the descriptions are not decisive against the TE. Before explaining why, let me outline a strategy the defender of the TE can adopt. Presented with a candidate nonobject involving property there are two responses. First, argue that the relevant property does not figure in the phenomenology. Second, if this cannot be maintained, argue that the relevant property is part of the intentional content, such that it seems to be a property of what the experience is directed toward, rather than a property of the experience itself. ${ }^{29}$

Let's apply this to the case in hand. We have a candidate for a non-object involving property of emotional experience, namely somatic properties. The defender of the TE should concede that there often are somatic properties in emotional phenomenology. In

\footnotetext{
${ }^{28}$ Deonna and Teroni's official position (2012: Ch.7; 2015: 293-311; 2017; 55-63) is that bodily feelings are part of the intentional attitude, and so would be properties of emotional paint (see section 3.4).

${ }^{29}$ See Tye 1995; I 55-। 59; 2002: |37-5 |; 20 |4: 39-57.
} 
fear, for example, subjects paradigmatically experience things like muscles freezing, heart jumping, etc. So, it is reasonable to suppose introspection would characterise those emotions' phenomenal character as including somatic properties. So, the first response is a non-starter.

However, we have not been given any decisive argument for taking these somatic properties to be non-object involving (as somatic latex), and so as supporting a claim of somatic opacity. The defender of the TE can insist that insofar as somatic properties figure in emotional experience, then introspective attention sees right through them in the sense that they seem to be properties of one's body (or parts thereof). Such 'internal' bodily objects are in important respects different from 'external' objects, and the relevant intentionality would be interoceptive rather than exteroceptive. Yet, somatic properties are not given as properties of the emotional experience itself. Rather, they are part of what emotional experiences are directed toward. As such, they contribute to their overall intentional content, as part of what gets 'encoded' into the content. 30

The defenders of somatic latex might respond that this involves ad-hoc adoption of a somatic feeling theory for the sake of defending the TE. Somatic feeling theories specify emotional experiences in terms of interoceptive awareness of somatic states, as the internal physiological condition of the body. ${ }^{31}$ Accordingly, the intentional object of emotional experience is the relevant bodily changes. Yet, even bracketing other problems with somatic feeling theories, the critic of the TE could highlight that this theory misses out the exteroceptive intentionality considered at the start of this section - emotions directedness towards particular objects - and in terms of which the TE was framed.

The best way for the defender of the TE to reply is to appeal to a distinction between 'hot' and 'cold' emotional experiences, and variability in the direction that introspection can take. If, as some philosophers and psychologists suggest, certain 'cool' and 'calm' emotions, such as admiration, awe, reverence, and regret, can occur without awareness of felt physiological changes - bodily changes being contingent rather than essential to them then in those cases there simply are no somatic properties that need accounting for ${ }^{32}$ In such cases, we can exhaustively account for the phenomenal character of the experience

\footnotetext{
30 See Tye 2002: I 43; 2008: 25-50; Seager 2002: 673; Kriegel 20। 5: 157.

${ }^{31}$ See James 1884: 188-205. Prinz (2004) argues for a neo-Jamesian theory according to which bodily feelings reliably track 'core relational themes' in the environment. As such bodily feeling is 'calibrated' to refer to an evaluative property, where such calibration is the result of evolutionary history and cultural learning.

32 See Lambie 2009: 272-280; Poellner 20 16: 13; James 1884: 191.
} 
in terms of the (apparent) particular object and its (evaluative) properties. Contrastingly, 'hot' emotional experiences include somatic properties. And in such cases, it makes sense for introspective attention to fear, say, to partly focus on what-it-feels-like to experience a jolt up your spine, or your heart jumping.

Yet it is arguably a mistake to construe such somatic properties as somatic latex rather than somatic content - or at least nothing forces that move. And further to this (mitigating the accusation of an appeal to somatic content being ad-hoc), it is plausible that introspective attention to 'hot' emotional experiences will involve accounting for both exteroceptive content (the particular objects and their evaluative or evaluatively-relevant properties) and interoceptive somatic content (somatic properties as qualifying parts of one's body). As such, positing somatic latex arguably rests on a failure to appreciate the complex (sometimes 'double') intentionality of emotional experience, and how this is reflected in introspection. ${ }^{33}$

Forestalling further objections, the relevant somatic properties of the 'internal' bodily objects, which introspective attention can (in the relevant cases) focus on, need not be atomistic in the sense of picking out a specific part of the body and a single somatic property; for example, a jolt up my spine. We can also appeal to the notions of a holistic bodily landscape or somatic field, such that the relevant somatic properties seem to qualify one's entire body. This explanation makes sense of the new father who reports feeling 'a great inner warmth'. He isn't singling out any specific body part as having a single somatic property; instead, he is attending to the way his whole body, his somatic profile, is presented. Building on this, introspective attention may deploy the relevant phenomenal concepts in a naïve way, or take metaphorical licence, as found in the attribution of 'warmth' (which presumably doesn't express increased felt temperature), or in expressions such as 'it feels like butterflies in one's stomach' (for anxiety).

Finally, variation in the way the bodily states and changes seem to subjects introspecting can reflect variation in introspective style. We can distinguish between analytic and synthetic introspection, where the former tends towards atomistic attention to specific body parts and their properties, with the latter tending toward holistic attention to overall bodily landscapes. ${ }^{34}$ Reflecting this, the way a trained physiologist or psychologist

\footnotetext{
${ }^{33}$ See Tye 2002: 143; 2008: 46-7; Seager 2002: 673.

${ }^{34}$ Marcel and Lambie 2002: 219-59.
} 
introspects (and reports) the relevant bodily changes will differ from the naïve and metaphorical way non-specialists do so.

Overall, this response to claims of somatic opacity (along the lines of somatic latex) is plausible, although it motivates an amendment to the TE:

Amended transparency claim for emotional experience (TE* hereafter): when $\mathrm{S}$ introspectively attends to their emotional experience the only properties $\mathbf{S}$ seems aware of are either evaluative properties of the 'external' particular object of the experience, or somatic properties of 'internal' bodily objects (including one's whole body, or parts thereof), or both.

As a final point on related issues, Anika Lutz claims it is not clear whether all of our metaphorical vocabulary really refers to bodily changes; consider, for example, the new father's claim that he feels like he could hug the world'. ${ }^{35}$ Such a report is compatible with the TE*. Often felt-action-readiness in emotional experience can be understood in terms of the particular object being given in terms of affordances, which can be specified as instrumental evaluative properties. In the relevant case, 'the world' seems to afford, or demand hugging. So, the putative motivational phenomenology can, in principle, also be placed in the exteroceptive intentional content. Although in such cases we might construe the particular object more broadly, as akin to an intentional situation. For example, the focus of my fear is the dog, its fearsome behaviour, and my spatial location, as an overall intentional situation which demands that I remove myself from it. Moreover, if there is also a bodily-state of action readiness, (e.g. muscle tensing), then on the TE* this can be part of what gets 'encoded' into the interoceptive content. ${ }^{36}$

Given the considerations of this section, the TE* is defensible pace the consensus in emotion theory. So, to argue for the opacity of emotional experience we should look beyond somatic latex.

\footnotetext{
35 Lutz 20। 5: 323.

36 This runs counter to Deonna and Teroni's (2012; Ch.7 2017: 55-63) claim that emotional paint should be specified in terms of felt bodily attitudes of action readiness - see end of section 3.4.
} 


\section{Emotional paint}

\section{I Arguing for mental paint}

This section argues that there is a kind of emotional paint which introspection on emotional experience reveals, therefore supporting a weak opacity claim for emotional experience. First, though, I consider non-emotional states, to get clearer on arguing for mental paint along the lines of intentional modes.

In the case of cognitive states, arguably two states can (i) share an intentional content, differing only in the relevant intentional attitude, and (ii) this attitude can be phenomenologically salient qua attitude. Consider the belief that <grass is green>. That content can figure as the same (propositional) content of different cognitive attitudes, such as supposing that <grass is green>. Let's accept that cognitive states, when consciously realized, have a cognitive phenomenology - there is something-it-is-like to occurrently believe or suppose that < grass is green>. However, there is a phenomenological difference between occurrently believing that grass is green and supposing it is. But since, ex hypothesi, the relevant difference cannot be captured in terms of a difference in content we need something else to explain it. One plausible candidate is what Terence Horgan and John Tienson call the phenomenology of attitude type. ${ }^{37}$ The idea is that the relevant intentional attitude, as a kind of mental paint, makes the phenomenological difference, contributing to the overall what-its-like-ness. Introspective attention to the experience would, therefore, specify the phenomenal character of the state as follows: 'the what-it's-like-ness of undergoing this specific propositional attitude vis-à-vis that specific intentional content'. ${ }^{38}$ So, phenomenal character seems to outrun intentional content and therefore the transparency claim will be false in this case.

Let's try something similar for sense-perceptual experiences. In the 1970s a waterbased covering called Artex was used to decorate ceilings, using swirling effects to produce a textured finish. As it happens, I'm in a room with an Artex ceiling. Looking up at the ceiling, I enjoy a visual experience which presents it as looking rough, and so which has the content <ceiling is rough>, granting roughness is a property that can be presented in visual experience. Intrigued by the look of the ceiling, I investigate further, reaching up to touch it. This time I enjoy a tactile experience which presents the ceiling as feeling rough, and so which also has the content <ceiling is rough>.

\footnotetext{
${ }^{37}$ See Horgan and Tienson 2002: 524.

38 Horgan and Tienson 2002: 524.
} 
If the content is the same, and yet there is a phenomenological difference - what-it-islike to see the ceiling as rough is different from what-it-is-like to feel the ceiling as rough then we need an explanation of that difference. Absent an appeal to intentional content which is (putatively) the same - one candidate is the phenomenology of the relevant intentional mode. What makes the phenomenological difference between the cases is that they are in different intentional modes; the first is in the visual mode, the second the tactile mode. And this phenomenology of intentional mode could (in each case) be revealed to introspection. ${ }^{39}$ So, phenomenal character seems to outrun intentional content and therefore the transparency claim will be false in this case.

For my purposes, I'm not concerned to analyse further whether the above arguments go through to support positing intentional modes as mental paint in these cases. With the strategy outlined, let's turn to emotional experiences. ${ }^{40}$

\subsection{Phenomenal contrast cases}

To set up the argument we need a phenomenal contrast case which putatively has the same (evaluative) content as emotional experience. Let's grant that there are nonemotional experiential states which represent evaluative properties. For example, nonemotional forms of evaluative perception: it is plausible that subjects can perceive objects as fearsome, beautiful, etc. without being emotionally moved. ${ }^{41}$

Let me say more about these non-emotional evaluative states. It has been suggested that we can enjoy non-emotional evaluative perceptions, as aspectual perceptual experiences (seeing under an aspect), as constituted by the subject's cares and concerns. Consider the following cases. ${ }^{42}$ Standing at the traffic lights, I am looking both ways, deciding when to cross. Just as I am about to cross a car approaches. I wait until it has passed, then safely walk to the other side. It is plausible that my perceptual experience involves a concern for personal well-being, or safety, or some such relevant 'concern'. Alternatively, consider a pilot captaining a plane. As the plane begins its descent phase to land on the runway, the pilot looks to see if the runway is clear, checks the speed and angle of descent,

\footnotetext{
39 See Crane 2000: 8-9; 2009: 480; Siewert 2003: 20, 29. Intentional modes should not be confused with Fregean modes of presentation which are aspects of intentional content.

40 See Tye 1995: I55-I 59; 2014: 47-48; Bain 2003: 517-8 and Speaks 2009: 545-553 for further discussion.

${ }^{41}$ I resist appeal to evaluative intuition since most accounts either take them to be forms of emotion or to be constituted by emotions (see Kauppinen 2013: 360-81; cf. Mulligan 2009: 58)

42 Amended from Goldie 2002 (see also Roberts 2013).
} 
and makes adjustments to land safely. Again, it is plausible that the perceptual experience involves a concern for well-being or safety. These examples point to experiences that are arguably (i) non-emotional, (ii) ubiquitous and (iii) have a kind of evaluative content.

Now consider the following case. An art critic visits the Louvre to see the Mona Lisa. Over several days, she spends her time studying the painting. On her first visit, she is emotionally moved by the painting, it strikes her as beautiful, and she experiences aesthetic admiration. However, as her trip draws to a close, she goes back to see the painting one last time. For whatever reason on this final occasion she is not emotionally moved. The painting, however, still looks (in the phenomenal sense) to be beautiful, but she experiences no emotion. When asked about the painting on this occasion she responds 'Ah yes, it's a beautiful piece', but things seem different from that first enthralling encounter.

So, we have phenomenal contrast cases. On the one hand, we have the emotional experience of aesthetic admiration, which represents the painting as beautiful, and on the other hand we have a non-emotional evaluative perceptual experience which likewise represents that painting as beautiful; paintings or other art-works, so the line of thought goes, can look beautiful, and nonetheless for whatever reason not precipitate admiration on particular occasions (in our case perhaps a kind of fatigue has set in). Note, even if one held that when our subject sees the painting without emotion there is a sense in which she doesn't see or appreciate its beauty, nonetheless she is plausibly described as recognizing it as beautiful (or perhaps knowing that it is beautiful). And the conception of experience we are working with, drawn from cases of non-emotional evaluative perception, is broad enough to encompass these attitudes. As such, in the second case, she at least has an experience which involves recognizing it as beautiful (as a kind of seeing as or seeing that with the relevant evaluative content).

There is undoubtedly a phenomenological difference between the cases. Yet if that is so - and if the evaluative content is the same - then we need an explanation of that difference. And one plausible explanation is that the emotional experience includes, as part of its phenomenal character, the relevant intentional attitude or mode. So, we are drawn to posit emotional paint.

A first response from the defender of the TE* could be that the relevant phenomenological difference is exclusively a difference in somatic intentional content. So, while both aesthetic admiration and evaluative perception represent the same evaluative property (as qualifying the same particular object), in the emotional case there are also somatic properties which are 'encoded' into the content, and are therefore part of the 
overall intentional content. However, as was claimed in 2.3, there are 'calm' emotional experiences, of which aesthetic admiration is one, that do not require co-present awareness of bodily feelings, and as such may be experienced without conscious awareness of somatic states. So, such a response is a non-starter.

Alternatively, can the defender of the TE* respond that there is, pace appearances, some other difference in intentional content? One option would be that in the emotional case the content has a for-me component, such that the painting seems beautiful-for-me, and no such self-referential component figures in the content of the evaluative perception (so the content would not be the same). However, this won't work. In emotional experience evaluative properties aren't typically experienced as relational in this sense, and introspection would not reveal them as such. While theoretical reflection on the fearsome or beautiful, may show it to be relational in nature - what is fearsome-for-me, isn't necessarily what's fearsome for a mouse - when emotion experientially presents its particular object as fearsome or beautiful, there is paradigmatically no (explicit) selfreference in the content of the experience. The situation is analogous to the so-called secondary qualities. Part of the phenomenology of visual experience is that colours are presented as non-relational monadic properties, appearing on the surfaces of external objects. And this phenomenological claim is unaffected even if colour properties turn out to be metaphysically relational. ${ }^{43}$

A more radical response would be to deny that non-emotional evaluative perception is intelligible as a mental state in itself, or as distinct from emotion. Perhaps the more plausible non-emotional state in our case is an evaluative judgement. If this could be maintained then the relevant phenomenological difference can be explained in terms of the difference between the structure of the content of non-doxastic states (i.e. the emotion) and doxastic states (i.e. the judgement) - for example, the latter may necessarily have conceptual content whereas the former need not. The defender of the TE* might, therefore, put pressure on the notion of a non-emotional evaluative perception, so blocking setting up the phenomenal contrast case.

However, consider the following amendment. Perhaps aesthetic admiration need not represent beauty per se, but a range of evaluatively-relevant, non-evaluative features. In the case of the painting, this might include the harmonious configuration of colours, the spatial representation of the figures, etc. These properties in some sense constitute the beauty of

${ }^{43}$ See Harman 1999: 1 - 17 and Shoemaker 1996: 253-4. 
the painting, although we need not assume beauty itself is experientially presented in the same way as those sensible properties are. Yet, it is undeniable that on that final day, when our art critic revisits the gallery and observes the painting, she perceives these sensible qualities. The painting still looks the same but does not move her. However, if the content is the same across the cases, and there is still a phenomenological difference between aesthetic admiration as directed towards the painting's non-evaluative (evaluativelyrelevant) sensible features, and a non-emotional visual experience of those same features, then we need an explanation for that difference. Again, the intentional mode, as a form of emotional paint, emerges as a plausible candidate to explain that difference.

Nonetheless, even granting we can run either of our phenomenal contrast cases (for evaluative and non-evaluative contents), we need to know more about emotional paint as an intentional mode. This is important since phenomenal contrast cases are open to dispute; it always seems possible for the defender of the TE to find a way of either forcing the relevant phenomenological difference into the content or blocking the contrast.

\subsection{Felt Valenced Attitudes}

Here is one proposal concerning the nature of emotional paint, although it is not a fulldress account - I provide that elsewhere. ${ }^{44}$ Let me begin with further phenomenological reflections about the feature of emotional experience I am interested in elucidating.

Think of an episode of anger in which I register the offensive character of a remark; in virtue of what aspect of my experience do I register such offensiveness? Or take an episode of amusement in which I register the humorous quality of an anecdote; in virtue of what aspect of my experience do I register the anecdote as funny? There is a range of cognate, paired, (bi)valenced attitude terms which roughly capture, across a range of cases, this aspect and arguably involve affectively registering the relevant evaluative properties. Here is a by no means exhaustive list: approval/disapproval, reject/accept, attraction/repulsion, like/dislike, approach/avoid, toward/away. Some of these attitude terms fit the affective dimension of specific emotional experiences better than others. For example, while felt disapproval is a good candidate in the case of indignation, it does not sound right for fear, given the moral connotations. Likewise, while attraction is a good candidate in the case of aesthetic admiration, it does not sound right for amusement.

${ }^{44}$ [Redacted]. 
Nonetheless, what is shared across cases is an occurrent attitude, as part of the emotional experience, which is conscious and valenced, such that they involve positively or negatively charged feelings as felt favourings or disfavourings (as a primitive 'yes' or 'no'). These felt valenced attitudes are intentional and monadic, targeting the particular object under an evaluative aspect (e.g. the colleague's offensive remark). Returning to our examples, take the case of anger: the experience includes felt disfavor, which affectively represents the disvalue of the offensive remark. Take the case of amusement: the experience includes felt favour, which affectively represents the value of the funny anecdote. So, felt valenced attitudes of (dis)favour are an exteroceptively directed, intentional component of emotional experience in virtue of which the subject affectively represents a particular object as possessing an evaluative property. As such, we can understand them as vehicles for the evaluative content of those experiences.

Here are some further features of the proposal. First, it precisifies our folk psychological concept of valence as present in emotions. A folk psychological understanding of (experiential) valence approximates to an orientation toward or away from pertinent features of one's environment, as an 'emotional warmth' which makes us aware of features of that environment which seem significant. It is this aspect of emotional experience which psychologists Marcel and Lambie label the 'experiential correspondence of significance'. ${ }^{45}$ The above proposal articulates this aspect more precisely. Felt valenced attitudes, which affectively represent value properties, are this experiential correspondence of significance.

Second, let me emphasize that such felt (dis)favourings are not evaluative properties of the object of the emotion, or part of the intentional content of the experience. Instead, they are the personal level vehicle for a content specified in terms of those properties. In this sense, the of in 'feelings of favour and disfavour' is one of specification (specifying the relevant attitude), rather than intentionality. ${ }^{46}$ As such, these felt valenced attitudes - if there are such - are not open to being placed into the intentional content of the emotional experience in the way somatic properties were. Insofar as they are part of the phenomenology of emotional experience then they seem to be (part of) what is doing the 'encoding', rather than what is getting 'encoded'; they are vehicles of evaluative representation, rather than something that are themselves represented.

\footnotetext{
${ }^{45}$ See Marcel and Lambie 2002: 244 and Poellner 2016: 6-7.

${ }^{46}$ Cf. Montague 2009: 24.
} 
Let me now say something about the connection between this proposal and affective intentionality approaches. First, note that the proposal goes beyond merely the observation that emotions are (or at least can be) intentional experiences. Rather, the appeal to felt valenced attitudes is closer to theorists who posit sui generis affective intentionality. The touchstone for such approaches is Goldie's enigmatic notion of feelings towards. Goldie's feelings towards are (arguably) supposed to capture the sui generis way emotional phenomenology and evaluative intentionality are connected, such that what-it-feels-like to experience a particular emotion is given in terms of the way the objects of emotions feel a specific evaluative way to their subjects (often without the presence of somatic feelings). As Goldie puts it, 'feeling towards is thinking of with feeling'. ${ }^{47}$ What precisely Goldie means is ambiguous, and the idea of emotional experience being constituted, in its affective component, by felt thinking, strikes an overly cognitive note. The felt valenced attitudes proposal is a substantive way of clarifying what the (non-cognitive) affective-intentional component of emotional phenomenology amounts to.

In sum, the proposal is that in emotional experience, there is necessarily a feeling of favour or disfavour in the uptake of the evaluative (or evaluatively-relevant) content. This feeling of favour or disfavour is a felt valenced, non-doxastic attitude towards the particular object of the emotion, which affectively represents the evaluative standing of that object. Yet these attitudes are neither presented in experience as characteristics of the object ('external' particular object or 'internal' bodily object) nor would an introspective report describe them as such. However, they are arguably an essential part of the phenomenal character of emotional experience and are connected to that feature which is commonly characterized as conscious valence; indeed, this is one way of characterizing the notion of personal level affectivity. Furthermore, on this proposal, even in cases where there are somatic components (whether somatic content, somatic latex, or perhaps even somatic paint, see end of 3.4) such components are not sufficient to explain the affectivity intentionality of emotional experience since even in those cases felt valenced attitudes are required as well. Simply put: felt valenced attitudes are supposed to be the essential component of affectivity in emotional experience.

Note, what has been presented is not a full defence of this proposal. Further questions remain such as (i) the plausibility of its generalizability to all human emotions and (ii) its connection with the subject's pre-existing 'cares and concerns' as embedded in the kinds

\footnotetext{
${ }^{47}$ Goldie 2000: 58. See also Helm 200 I; Döring 2003: 214-30; Slaby 2008: 429-44.
} 
of evaluative appraisals - those automatic, and nonconscious states which typically precede emotion - emphasised in emotion psychology and affective science. For sake of brevity, I pass over saying more on these issues here and turn back to considerations of opacity.

\subsection{Felt Valenced Attitudes and Opacity}

Returning to our central example, consider the case of aesthetic admiration for the Mona Lisa on the proposal: when introspectively attending to the experience our art-critic would (mostly) attend to (apparent) evaluative features of the painting - say its beauty (and perhaps other non-evaluative, evaluatively-relevant features). Yet they would also attend to their felt favour toward it, under this evaluative aspect. As such, they would not just specify the phenomenal character of the experience in terms of evaluative properties of the painting (the exteroceptive intentional content), but also in terms of their felt valenced attitude ('approval' or 'favour') towards that evaluative property. So, on this proposal, emotional paint is specified in terms of felt valenced intentional attitudes.

Positing emotional paint in these terms therefore gives us a neat explanation of the relevant phenomenological difference for phenomenal contrast cases. If we can hold evaluative intentional content fixed between emotional and non-emotional experiences, then we can claim that what makes the relevant phenomenological difference is the presence (or not) of the relevant felt valenced attitudes. Note, the account could be extended to deal with cases of emotions that are not felt and their counterparts with the same content (or in less committal terms 'information'). The relevant difference would not be felt valenced attitudes but valenced attitudes per se. Such valence might plausibly be evidenced behaviourally, but it would be the appeal to valenced attitudes as present in the emotional case that would explain the relevant differences between states with the same content. Such attitudes would then also be appealed to in explaining what the 'feeling of valence' consists in when the emotions are, as has been my focus here, felt.

If this view is along the right lines - emotional experiences involving emotional paint in terms of affective-attitudinal vehicles - then the consequences for the TE* are significant. The phenomenal character of emotional experience would include components that don't figure as properties in the content and yet which play an intentional role (i.e. as emotional paint). So it is not open to the defender of the TE* to claim that such experiences are attitude transparent, such that in introspecting them there would be no phenomenology of attitude-type. Rather, the intentional mode would be non-transparent since the way 
evaluative properties are represented in emotional experience is on the basis of felt valenced affective attitudes.

The only way for the defender of the TE* to respond is to deny there are such felt valenced attitudes (or similar forms of emotional paint) in emotional phenomenology. But for this to convince we would need (i) a plausible explanation of the phenomenological differences in those phenomenal contrast cases, and (ii) a non-question begging argument for why it is even prima facie plausible that all relevant dimensions of experiential affectivity can be cashed out in terms of intentional content (i.e. one that doesn't assume the TE*). On this second issue, the defender of emotional paint can argue that we risk not merely ignoring our folk psychological concept of conscious affectivity, but also our experience thereof (presumably on which the folk concept is based), which includes the experience of being acted on, or moved by something (felt valenced attitudes are one way of capturing this).

So, on the view under consideration, emotional experiences involve emotional paint of a specific kind. Introspective attention to the experience would specify the phenomenal character as follows: 'the what-its-like-ness of enjoying this specific felt valenced attitude vis-à-vis that specific evaluative intentional content'. If this is correct, then the weak opacity claim as applied to emotional experience (with the relevant amendments) is correct:

Weak opacity claim applied to emotional experience: when S introspectively attends to their emotional experience, the properties $S$ seems aware of are evaluative properties of the particular object of the experience, and in certain cases also somatic properties of 'internal' bodily objects. Further to this, the experience still seems to be of something that has those properties, rather than itself having those properties. Yet, there are also non-object involving properties S seems aware of that aren't (apparent) object-properties. Specifically, S seems aware of emotional paint, along the lines of felt valenced attitudes towards the relevant evaluative properties.

This suggests emotional experience can be characterized as involving a specific kind of opacity, namely attitudinal opacity. So, pace the consensus in emotion theory, emotional opacity would be attitudinal, not somatic.

In closing let me note a different way to theorize emotional paint which still gets us a version of the weak opacity claim, and so attitudinal opacity. According to the bodilyattitudinal theory of emotion defended by Deonna and Teroni, emotions are felt bodily 
attitudes of action readiness. ${ }^{48}$ The relevant bodily phenomenology is not, pace the somatic feeling theory, that of 'atomistic' bodily changes. Rather, it is holistic and action-ready, integrating information from different sources, combining into a synthetic bodily feel - as a putative bodily gestalt. Further contrasting with somatic feeling theories, in which the emotion is about the somatic changes (as interoceptive experiences), emotional experience is claimed to be intentionally about 'the world' not 'the body', but nonetheless about the world in a bodily way. Emotional experience, so understood as a bodily-attitude (manifest as a holistic action-ready bodily phenomenology) targets the relevant 'worldly' particular objects, and so has the relevant (evaluatively-significant) content.

On this picture, emotional experiences have an attitudinal phenomenology. However, in contrast to the felt valenced attitudes proposal, the relevant attitudes are bodily. There are other features of this account - such as its denial that emotional experience necessarily has evaluative intentional content - which need not concern us here. What bears emphasizing is that on this view, emotional experiences are not attitude transparent - they involve emotional paint as somatic paint. This account therefore gets us a version of the weak opacity claim, such that when S introspects their emotional experience, amongst others things, $\mathrm{S}$ is aware of somatic paint, along the lines of felt bodily attitudes of action readiness towards the relevant (evaluatively-significant) properties of the object of the experience. ${ }^{49}$ There is more than could be said concerning how this view compares with the non-bodily proposal of emotions' affective character in terms of felt valenced attitudes. However, regardless of which proposal we find more plausible emotional experience is attitudinally opaque.

\section{Concluding Remarks}

What has been presented here is not a knock-down argument against the TE* or decisive considerations in favour of my preferred account of the phenomenal character of emotional experience. However, the TE* encounters significant problems relating to providing a satisfactory explanation of phenomenal contrast cases, and giving a plausible account of conscious affectivity. Unless these problems can be overcome then, alongside the ability of emotional paint to provide prima facie plausible solutions to these problems, there is a presumption in favour of the view that emotional experience is attitudinally

\footnotetext{
${ }^{48}$ See Deonna and Teroni 2012: Ch.7; 2015: 293-31।; 2017 55-63. See [Redacted] for critical discussion.

49 Deonna and Teroni 2015: 308.
} 
opaque. Importantly, if emotional experiences are attitudinally opaque, it follows that the transparency claim cannot be upheld across the board - it is false for one important class of intentional experiences.

It remains to be said what the implications of attitudinal opacity are for different theories of emotion - detailing that is a matter for another paper. However, attitudinal opacity does lend support to a manifest attitudinal theory. That is a theory on which the non-transparent attitude (or mode) and the intentional content constitute the phenomenal character of emotional experiences. I have outlined one such proposal that I prefer, through the notion of felt valenced intentional attitudes.

\section{References}

Bain, D. (2003) 'Intentionalism and Pain' in Philosophical Quarterly 53 (213): 502-523.

Block, N. (1996) 'Mental Paint and Mental Latex' in Philosophical Issues 7, 19-49. Atascadero, CA: Ridgeview.

- (2003) 'Mental paint' in M. Hahn \& B. Ramberg (eds.), Essays on the Philosophy of Tyler Burge, 165-200. Cambridge: MIT Press.

Crane, T. (2000) Introspection, Intentionality and the Transparency of Experience' in Philosophical Topics, 28, 49-67.

- (2009) 'Intentionalism' in A. Beckermann and B.P. McLaughlin, (eds.), The Oxford Handbook of the Philosophy of Mind, 474-93. Oxford: Oxford University Press.

Deonna, J. and Teroni, F. (2012) An Introduction to the Philosophy of the Emotions. London: Routledge.

- (2015) 'Emotions as Attitudes' in dialectica 69 (3), 293-31 I.

- (2017) 'Getting Bodily Feelings into Emotional Experience in the Right Way' in Emotion Review $9(1), 55-63$

Dennett, D. (1988) 'Quining Qualia' in Anthony J. Marcel \& E. Bisiach (eds.), Consciousness in Contemporary Science. Oxford: Oxford University Press (1988).

De Sousa, R (1987) The Rationality of Emotion. MIT: MIT Press.

- (2004) 'Emotions - What I Know, What l'd Like to Think I Know, and What l'd Like to Think' in R. C. Solomon, (ed.) Thinking about Feeling, 61-75 Oxford: Oxford University Press.

Döring, S. (2003) 'Explaining Action by Emotion' in Philosophical Quarterly 53 (21 I): 214-30.

Dretske, F. (1999) Perception, Knowledge and Belief, 158-177. Cambridge: Cambridge University Press.

Goldie, P. (2000). The Emotions. Oxford. Oxford University Press.

- (2002) 'Emotions, feelings and intentionality' in Phenomenology and the Cognitive Sciences (I), $235-54$. 
Gow, L. (2016) 'The Limitation of Perceptual Transparency' in Philosophical Quarterly 66 (265): 723 744.

Harman, G. (1990) 'The intrinsic quality of experience' in Philosophical Perspectives 4, 31-52.

_ (1996) 'Explaining Objective Color in Terms of Subjective Reactions' in Philosophical Issues, (7), $1-17$.

Helm, B. (200 I) Emotional Reason. Cambridge: Cambridge University Press.

Horgan, T., and Tienson, J. (2002) 'The Intentionality of Phenomenology and the Phenomenology of Intentionality', in D. Chalmers (ed.) Philosophy of Mind: Classical and Contemporary Readings, 520-33. Oxford: Oxford University Press.

James, W. (1884) 'What Is an Emotion?' in Mind, 9, pp. 188-205.

Kauppinen, A. (2013) 'A Humean Theory of Moral Intuition' in Canadian Journal of Philosophy 43 (3): $360-81$.

Kenny, A. (1963) Action, Emotion and Will. London: Routledge.

Kennedy, M. (2009) 'Heirs of Nothing: The Implications of Transparency' in Philosophy and Phenomenological Research 79 (3); 574-604.

Kriegel, U. (2015) The Varieties of Consciousness. Oxford: Oxford University Press.

Kind, A. (2003) 'What's so transparent about transparency?' in Philosophical Studies, I I , 225-244.

Lambie, J. (2009) 'Emotion Experience, Rational Action, and Self-Knowledge', in Emotion Review I (3): $272-80$.

Lyons, W. (1980) Emotions. Cambridge: Cambridge University Press.

Lutz, A. (2015) 'The Phenomenal Character of Emotional Experience: A Look at Perception Theory' in dialectica 69 (3): 313-334.

Marcel J. A., and Lambie, J. A. (2002) 'Consciousness and the Varieties of Emotion Experience: A Theoretical Framework' in Psychological Review 109 (2), 219-59.

Martin, M. (1998) 'Setting Things Before the Minds' in Anthony O'Hear (ed.) Current Issues in Philosophy of Mind, 157-79. Cambridge: Cambridge University Press

- (2002) 'The Transparency of Experience' in Mind and Language, 4(4), 376-425.

Moore, G. E. (1903). 'The refutation of idealism' in Mind, 12, 433-453.

Montague, M. (2009) 'The Logic, Intentionality, and Phenomenology of Emotion' in Philosophical Studies | 45 (2), |7|-92.

Mulligan, K. (2009) 'On Being Struck by Value', in B. Merker, ed., Leben mit Gefühlen: Emotionen, Werte und ihre Kritik, Paderborn: Mentis, |4|-16|.

Peacocke, C. (1983) Sense and content. Oxford: Oxford University Press.

Poellner, P. (2016) 'Phenomenology and the Perceptual Model of Emotion' in Proceedings of the Aristotelian Society, Vol. CXVI, Part 3, I-28.

Prinz, J. (2004) Gut Reactions: A Perceptual Theory of Emotions. Oxford: Oxford University Press. 
Roberts, R. (2013) Emotions in the Moral Life. Cambridge: Cambridge University Press.

Salmela, M. (201 I) 'Can Emotion be Modelled on Perception?' in dialectica 65, I-29.

Seagar, W. (2002) 'Emotional Introspection' in Consciousness and Cognition II, 666-687.

Searle, J. (1983) Intentionality: An Essay in the Philosophy of Mind. New York: Cambridge University Press.

Shoemaker, S. (1996) The First-Person Perspective and Other Essays. Cambridge: Cambridge University Press.

Siewert, C. (2003) 'Is experience transparent?' in Philosophical Studies, 117, 15-41.

Slaby, J. (2008) 'Affective Intentionality and the Feeling Body' in Phenomenology and the Cognitive Sciences 7 (4), 429-44.

Speaks, J. (2009). 'Transparency, intentionalism, and the nature of perceptual content' in Philosophy and Phenomenological Research, 79, 539-573.

Tappolet, C. (2016) Emotions, Values and Agency. Oxford: Oxford University Press.

Teroni, F. (2007) 'Emotions and Formal Objects' in dialectica 6 I (3), 395-4I5.

Tye, M. (1995). Ten problems of consciousness. Cambridge: The MIT Press.

- (2002) 'Representationalism and the Transparency of Experience' in Nous 36 ( I): I37-5 I.

- (2008) 'The Experience of Emotion: An Intentionalist Theory', in Revue Internationale de Philosophie, 24, 25-50.

- (2014) 'Transparency, Qualia Realism and Representationalism' in Philosophical Studies, 170: 3957. 